\title{
Action Research on The Effectiveness of Autonomous Practices Upon Learning Outcomes
}

\author{
Kaisar Katchi', Rita Das ${ }^{2}$, Chandrashekhar Gajbhiye ${ }^{3}$ \\ ${ }^{1,2,3}$ Applied Sciences and Humanities Department, Sardar Patel Institute of Technology, \\ Bhavan's Andheri Campus, Munshi Nagar, Andheri West, Mumbai 400053 \\ ${ }^{1}$ kaisar_katchi@spit.ac.in \\ ${ }^{2}$ rita_das@spit.ac.in \\ ${ }^{3}$ c_gajbhiye@spit.ac.in
}

\begin{abstract}
This paper presents a comparative study between the results obtained by two groups of students for a problem-based subject over two different systems of learning: the traditional, classroom-based delivery, and a system coupling that with a more interactive tutorial-based approach. The results show an improvement in the grade performance with the newer, interactive approach.
\end{abstract}

Keywords: Outcome based education, interactive teaching, action research

\section{Introduction}

The curriculum of an institution is a living entity. It evolves with time, reflecting the ever-changing needs of the society and keeps pace with the growing talent of the learners and the faculty. The objective of the curriculum is to develop professionals with competencies, intellectual skills and knowledge. These days the focus is on outcome based education (OBE), the purpose of which is to create a teaching and learning environment that would produce knowledgeable, creative and skilled professionals with positive values and attitude.

\section{Kaisar Katchi}

Applied Sciences and Humanities Department, Sardar Patel Institute of Technology, Bhavan's Andheri Campus, Munshi Nagar, Andheri West, Mumbai 400053

kaisar_katchi@spit.ac.in

\section{A. OBE Principles}

An OBE curriculum gives a clear picture of what is important for learners to be able to do, and insights on how to then structure the curriculum, teaching learning and evaluation for effective learning. The four basic principles of outcome based education proposed by Spady (1994) are:

1) Clarity of focus: Everything that teachers do must be clearly directed and focused on what they want students to know, understand and be able to do. Teachers should focus on helping students to develop the knowledge, skills and personalities that will enable them to achieve the intended outcomes that have been clearly articulated.

2) Designing down: The curriculum design must start with a clear definition of the intended outcomes that students are to achieve by the end of the program. Once this has been done, all instructional decisions are then made to ensure achieving this desired end result.

3) High expectations: Teachers should establish high and challenging standards of performance in order to encourage students to engage deeply in what they are learning. Helping students to achieve high standards is linked very closely with the idea that successful learning promotes more successful learning.

4) Expanded opportunities: Teachers must strive to provide expanded opportunities for all students. This principle is based on the idea that not all learners can 
learn the same thing in the same way and in the same time. However, most students can achieve high standards if they are given appropriate opportunities.

As per National Board of Accreditation (NBA) there are 12 Program Outcomes (POs) based on graduate attributes. Out of the $12 \mathrm{POs}$, the focus in this paper is on PO no. 2 which is "Problem Analysis: Identify, formulate, research literature and analyze engineering problems to arrive at substantiated conclusions using first principles of mathematics, natural and engineering sciences."

To attain the program outcome on problem analysis, course outcomes on problem solving of the specific courses should be attainable. To attain them, one needs to strengthen the problem-solving skills of learners.

\section{Methodology}

While designing the curriculum of first year engineering students under autonomy, the relevant program outcomes were considered. To develop problem solving skills, tutorials were introduced for the Engineering Mechanics course. This course is chosen as it is problem oriented. The action research methodologies are chosen according to guidelines provided by Sax and Fisher (2001), Sagor (2011) and Johnson (1995). The theory section of this course is for three hours per week. There are four first year classes of different disciplines in the institute chosen for study presently. The number of students in each class is around 63. There are 16 students for tutorials in each batch; which is one-fourth of the total strength of each class.

Tutorials are interactive problem-solving sessions. They help to build a better connect with the teacher as the batches consist of a small group of learners. Individual attention is given to the learners to develop problem solving skills. The doubts of theory lectures, if any, are discussed. Learners are encouraged to discuss and ask questions. A few challenging problems are also discussed and then solved. It makes learners think and solve on their own. There is no evaluation of tutorials in the current scheme; a deliberate decision.

Fig. 1 shows a sample tutorial problem, based on equilibrium of beams, which is a prominent part of Engineering Mechanics. The problems typically provide various loads on a rigid beam structure and ask the student to find the support reactions necessary to keep the beam structure from deflecting, or moving; i.e., the supports required to maintain static equilibrium.

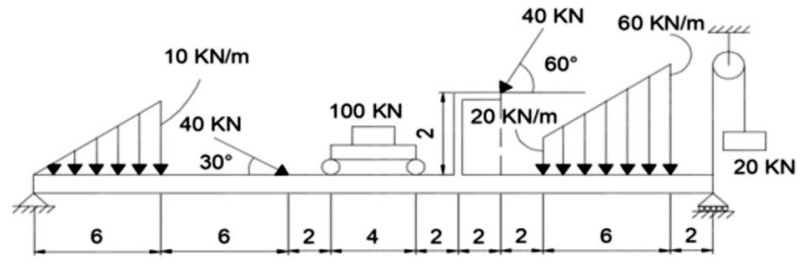

Fig. 1: Sample Tutorial Problem

There are multiple ways in which the batches attempted such problems. In one session they might be asked to further subdivide into smaller groups of 4 , and then find the net load of smaller portions of the beam, which would later be tallied into the overall load pattern. In others, each group might be asked to find these reactions for the same loading assembly, but with different types of supports, placed at different locations under the beam. The floor was kept open to decide what would become the best location for the supports.

With such preparation, it was expected that the students would be ready to attempt problems in the end semester exam for a beam placed under any load assembly, for any support assembly.

To observe improvement in learning and problemsolving skills, the detailed result analysis is done of the Engineering Mechanics course. The end semester exam results are chosen instead of other assessment parameters (such as oral exams and in-semester evaluations; both of which are also a part of the Engineering Mechanics course and scheme) for two reasons: first, every student attempts the same paper for the same time duration at the same time for an academic year (AY), guaranteeing uniformity of the examination process. Second, since the evaluation of the answer papers is done blind (the student's identification details of each answer paper are masked with black paper before assessment), any direct or indirect bias is removed from the evaluation process.

The parameters to observe improvement (chosen by studying Kemmis et al's (2013) research) in problem solving skills are: average marks of all students, percentage of students getting above average marks, and the percentage of students getting 
Table 1. Comparison of Marks and Averages Per Class

\begin{tabular}{|c|c|c|c|c|c|c|c|c|c|c|c|c|}
\hline \multirow[t]{2}{*}{$\begin{array}{c}\text { Marks } \\
\text { (out of 100) }\end{array}$} & \multicolumn{3}{|c|}{ Electronics } & \multicolumn{3}{|c|}{ EXTC } & \multicolumn{3}{|c|}{ IT } & \multicolumn{3}{|c|}{ Computers } \\
\hline & $16-17$ & $17-18$ & \%Diff* & $16-17$ & $17-18$ & $\%$ Diff & $16-17$ & $17-18$ & $\%$ Diff & $16-17$ & $17-18$ & $\%$ Diff \\
\hline $\begin{array}{c}80 \text { and above } \\
(\mathrm{O})\end{array}$ & 9 & 6 & -33.33 & 6 & 5 & -16.67 & 16 & 7 & -56.25 & 17 & 15 & -11.76 \\
\hline 75 to $79(\mathrm{~A})$ & 2 & 7 & 250.00 & 2 & 6 & 200.00 & 7 & 8 & 14.29 & 9 & 10 & 11.11 \\
\hline 65 to $74(\mathrm{~B})$ & 5 & 13 & 160.00 & 17 & 9 & -47.06 & 12 & 16 & 33.33 & 13 & 17 & 30.77 \\
\hline 55 to $64(\mathrm{C})$ & 11 & 14 & 27.27 & 12 & 15 & 25.00 & 12 & 12 & 0.00 & 18 & 8 & -55.56 \\
\hline 40 to $54(\mathrm{D})$ & 22 & 13 & -40.91 & 16 & 19 & 18.75 & 13 & 17 & 30.77 & 9 & 5 & -44.44 \\
\hline below $40(\mathrm{E})$ & 13 & 9 & -30.77 & 8 & 8 & 0.00 & 7 & 3 & -57.14 & 2 & 10 & 400.00 \\
\hline \multicolumn{13}{|c|}{$* \%$ Diff $=$ percentage difference } \\
\hline Class Average & 51.95 & 59.08 & 13.72 & 57.30 & 57.24 & -0.09 & 63.66 & 62.65 & -1.58 & 68.00 & 64.94 & -4.50 \\
\hline $\begin{array}{c}\% \text { above } \\
\text { average }\end{array}$ & 73.77 & 56.45 & -23.48 & 55.74 & 51.61 & -7.40 & 53.73 & 55.56 & 3.40 & 50.00 & 64.62 & 29.23 \\
\hline
\end{tabular}

the highest grade, which is "O" (outstanding grade, equivalent to 10 points on a 10 -point system).

The first two criteria are also used to calculate course attainment as per NBA norms. The sample size of learners for the present study is 258 (for AY 201617) and 252 (for AY 2017-18).

\section{Observations}

Table 1 presents the comparison of grade-wise breakdown, class average, and percentage of students with average or above average marks for the Engineering Mechanics course for AY 2016-17 and 2017-18 for each individual class. Table 2 present the overall analysis for the entire sample size. Figures 2 and 3 present the cumulative bar graphs for the results of AY 2016-17 and 2017-18 respectively. The class average of the Engineering Mechanics course is higher in the 2017-18 batch as compared to the 201617 batch as shown in Figure 4.

Table 2. Comparison of Marks and Average for The Entire Sample Set

\begin{tabular}{|c|r|r|r|}
\hline Marks (out of 100) & \multicolumn{3}{|c|}{ Overall } \\
\hline & \multicolumn{1}{|c|}{$\mathbf{1 6 - 1 7}$} & \multicolumn{1}{|c|}{$\mathbf{1 7}$} & \multicolumn{1}{c|}{ \%Diff } \\
\hline 80 and above (O) & 48 & 33 & -31.25 \\
\hline 75 to 79 (A) & 20 & 31 & 55.00 \\
\hline 65 to 74 (B) & 47 & 55 & 17.02 \\
\hline 55 to 64 (C) & 53 & 49 & -7.55 \\
\hline 40 to 54 (D) & 60 & 54 & -10.00 \\
\hline below 40 (E) & 30 & 30 & 0.00 \\
\hline & & & \\
\hline Class Average & 60.41 & 61.03 & 1.03 \\
\hline \% above average & 53.1 & 55.95 & 5.37 \\
\hline
\end{tabular}

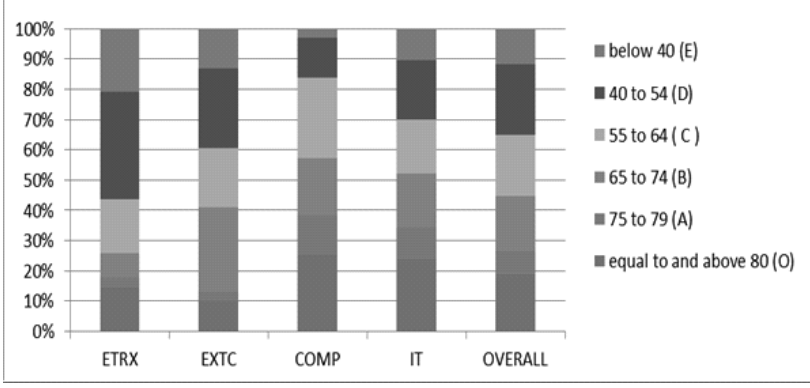

Fig.2 : Grade Distribution for the year 2016-17

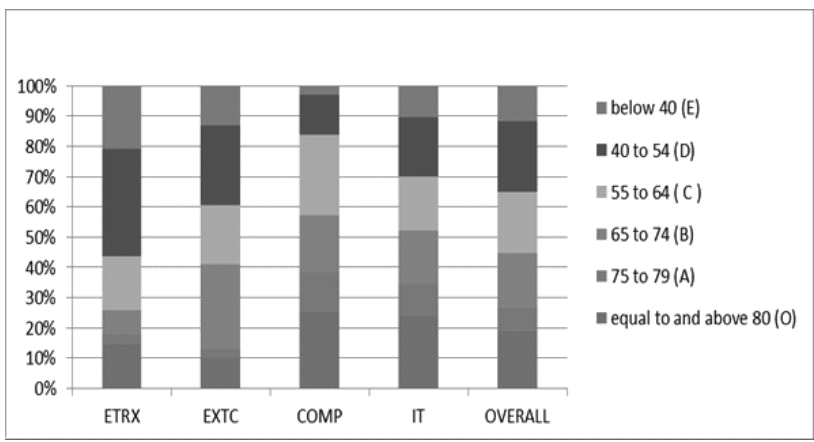

Fig. 3 : Grade Distribution for the year 2017-18

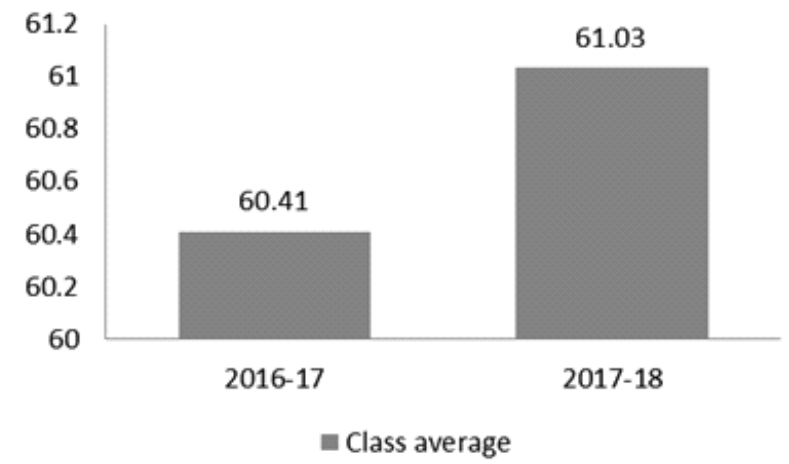

Fig. 4: Comparison of Class Average 
The percentage of students getting above average marks is also higher in the 2017-18 batch compared to the 2016-17 batch (ref. Figure 5).

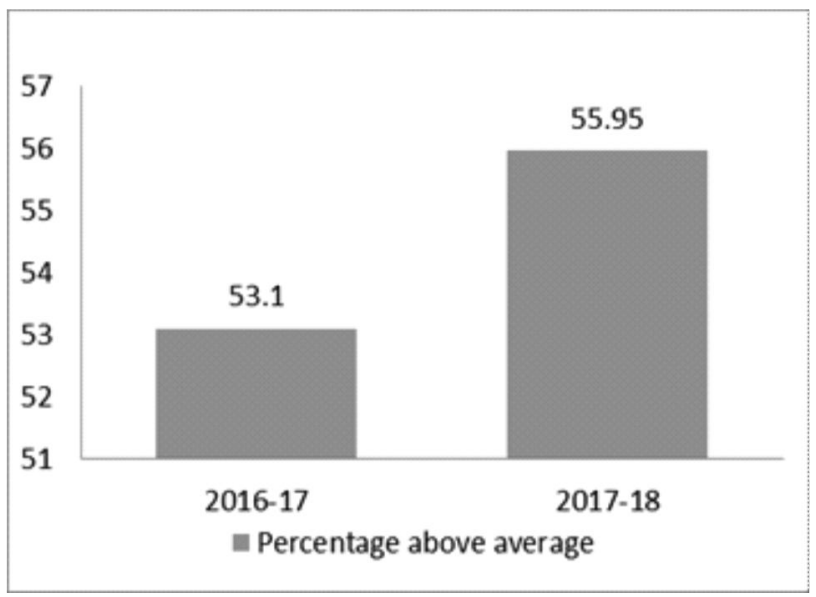

Fig.5 : Comparison of percentage of students with marks above class average

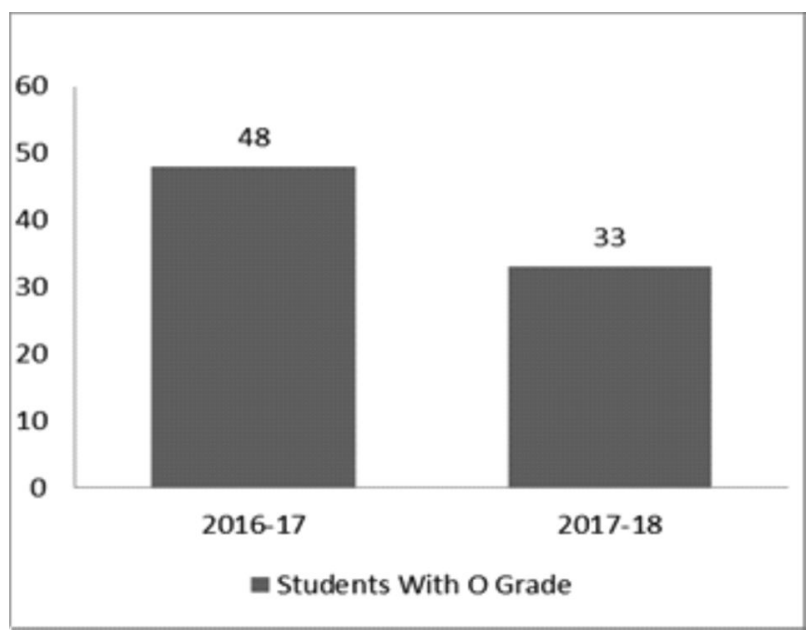

Fig.6:Comparison of number of students with $\mathrm{O}$ grade

The percentage of students getting the outstanding grade has reduced (ref. Figure 6) but the number of students getting A (equivalent to 9) grade has increased in the Engineering Mechanics course (ref. Table 2) from 20 in the AY 2016-17 to 31 in the AY 2017-18. The number of students getting B (equivalent to 7) grade has increased in the Engineering Mechanics course (ref. Table 2) from 47 in AY 2016-17 to 55 in AY 2017-18. On the other hand, the number of students securing $\mathrm{C}$ and $\mathrm{D}$ grades has reduced in AY 2017-18 compared to AY 2016-17, while the number of students with less than 40 marks remains the same for both years, suggesting that there has been an observable improvement in the students' grades without negatively affecting the total passing percentage of the class.

\section{Conclusion}

Since the total number of students with less than 40 marks remains the same and there is a net reduction in the number of students securing $C$ and $D$ grades, this suggests that while there has been an enhancement in the quality of paper setting and evaluation, making it tougher to secure an $\mathrm{O}$ grade, the continuous problem solving tutorial sessions are evidently beneficial in improving the overall grade performance of the entire set of learners, increasing the number of students securing A and B grades.

These benefits occur due to the following reasons: the smaller group of sixteen students, the devoted time slot for problem solving, and the higher degree of personal interaction in the tutorial sessions seems to be a useful tool in helping the learners acquaint themselves with the problem solving methodology for subjects such as Engineering Mechanics, offering them more opportunities to grasp concepts and clear doubts that they may not be able to in classroom lectures, which have a strength of over sixty students. Along similar lines, the teacher may find it more effective to target slow and fast learners, and assign problems of respective levels to both, in these smaller, focused sessions.

\section{Future Scope}

It would be useful to conduct this study over the oncoming AY (2019 and beyond), in order to get a more prominent trend. It would also be useful to observe the effects of an interactive, tutorial-based approach on subjects with a higher amount of theoretical content than Engineering Mechanics, in order to develop better techniques in the teachinglearning methodologies for the same.

\section{References}

[1] Spady, William G. (1994), Outcome-Based Education: Critical Issues and Answers, American Association of School Administrators, 1801 North Moore Street, Arlington, VA 22209 (Stock No. 2100488).

[2] Sax, C., and Fisher, D. (2001). Using qualitative action research to effect change: Implications for professional education. Teacher Education Quarterly, 71-80. 
[3] Sagor, R. (2011). The action research guidebook: A four-stage process for educators and school teams. Corwin Press.

[4] Johnson, B. M. (1995). Why Conduct Action Research?. Teaching and Change, 3(1), 90-104.

[5] Kemmis, S., McTaggart, R., and Nixon, R. (2013).
The action research planner: Doing critical participatory action research. Springer Science \& Business Media.

[6] NBA User Manual, http://www.nbaind.org/en/usermanual.htm 